\title{
VISUAL EVOKED POTENTIAL AS AN ELECTROPHYSIOLOGIC TOOL IN MIGRAINE
}

\author{
Bindu Sundar'1, Assalatha G², Sahila M³, Thomas Iype 4
}

${ }_{1}^{1}$ Associate Professor, Department of Physiology, Government Medical College, Kottayam.

${ }^{2}$ Former Professor and HOD, Department of Physiology, Government Medical College, Thiruvananthapuram.

3 Professor, Department of Physiology, Government Medical College, Thiruvananthapuram.

${ }^{4}$ Professor and HOD, Department of Neurology, Government Medical College, Thiruvananthapuram.

\section{ABSTRACT}

\section{BACKGROUND}

Visual Evoked Potential may be a useful method for understanding the pathophysiologic mechanisms involved in the genesis of migraine.

In this study, VEP was evaluated as a tool to assess visual function in migraine with aura and without aura.

\section{MATERIALS AND METHODS}

35 migraine patients ( 25 without aura and 10 with aura) and equal number of healthy controls were enrolled in the study. Pattern Reversal VEP using a checker board was performed and compared in the three groups. The latency and amplitude of P100, the most consistent and prominent wave of VEP were analysed. VEP parameters in migraine patients were correlated to frequency of attacks and disease duration.

Design- Descriptive study.

\section{RESULTS}

Migraine patients with aura showed significantly prolonged VEP P100 latency compared with migraine without aura and control groups. VEP P100 latency showed significant positive correlation with both the duration and frequency of migraine attacks, the latency increasing with increased duration of migraine and more frequent attacks.

\section{CONCLUSION}

There is involvement of the visual system in migraine with aura rather than migraine without aura. VEP could be regarded as a useful and reliable technique for assessment of the visual dysfunction in migraine, manifesting predominantly by prolongation of P100 latency.

\section{KEYWORDS}

Migraine, Evoked potential, Visual, Latency, Amplitude, Cortical.

HOW TO CITE THIS ARTICLE: Sundar B, Assalatha G, Sahila M, et al. Visual evoked potential as an electrophysiologic tool in migraine. J. Evolution Med. Dent. Sci. 2017;6(15):1230-1234, DOI: 10.14260/Jemds/2017/267

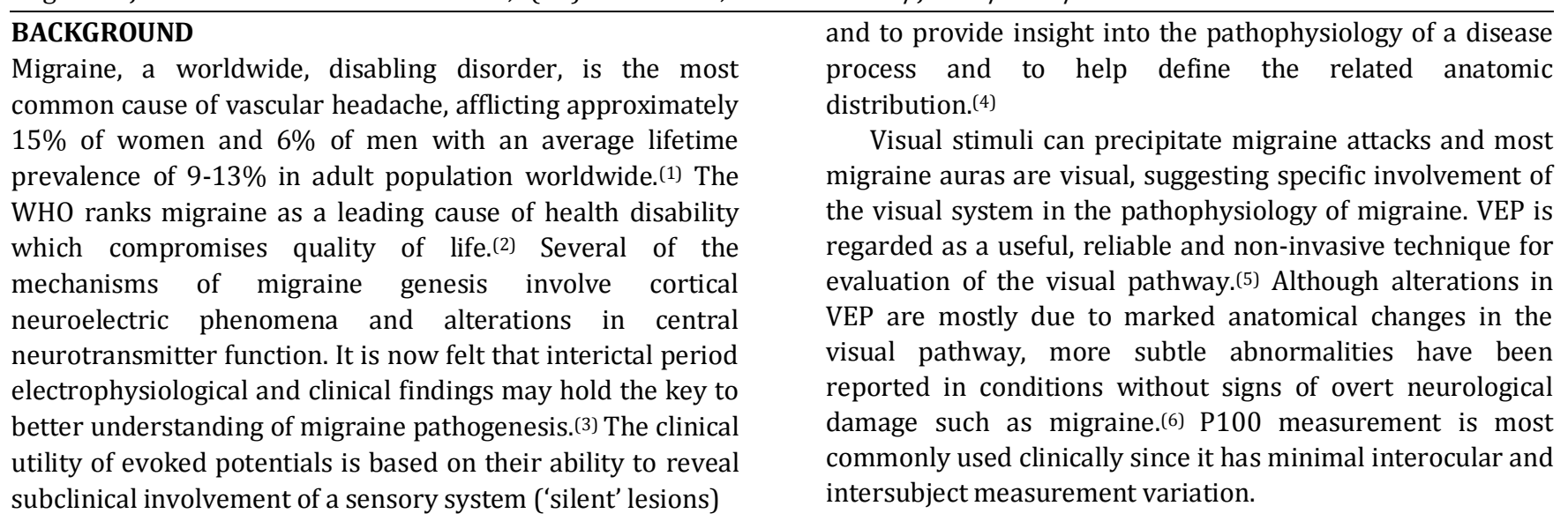

Financial or Other, Competing Interest: None.

Submission 12-12-2016, Peer Review 04-02-2017,

Acceptance 10-02-2017, Published 20-02-2017.

Corresponding Author:

Dr. Thomas Iype,

Professor and HOD,

Department of Neurology,

Government Medical College,

Thiruvananthapuram.

E-mail: beenaiype@gmail.com

DOI: $10.14260 /$ jemds $/ 2017 / 267$

\section{Aims and Objectives}

1. To evaluate variations in VEP P100 latency and amplitude in adult migraine patients with and without aura compared to healthy subjects.

2. To correlate variations in VEP to disease duration and frequency of migraine.

\section{MATERIALS AND METHODS \\ Subjects/ Sample size}

The study group (cases) comprised of 35 migraine patients (21 females and 14 males) aged 18 to 40 years who attended Neurology Outpatient Clinic, Govt. Medical College, 
Thiruvananthapuram, clinically diagnosed with migraine according to criteria set by the Headache Classification Committee of the International Headache Society (IHS II2004).(7) The study group was divided into two subgroups: Migraine with aura ( 7 females and 3 males) and Migraine patients without aura (14 females and 11 males) based on criteria of IHS II 2004. The control group consisted of 35 age matched healthy volunteers (16 females and 19 males) with no history of headaches.

\section{Inclusion Criteria}

Adult males and females of 18 to 40 years diagnosed with migraine and have not received prophylactic therapy for migraine.

\section{Exclusion Criteria}

- Less than 72 hours after headache.

- Visual acuity $<20 / 200$.

- Nystagmus.

- Strabismus.

- Anisocoria.

- Use of miotics or mydriatics within 12 hours.

- Diseases affecting visual pathway.

- Diabetes mellitus.

- $\quad$ Epilepsy \& Antiepileptic therapy

- History of cerebrovascular accident.

Migraine cases of age 18 to 40 years were enrolled because age has been reported to influence the latency of P100 at a rate of $2.5 \mathrm{~ms} /$ decade after the fifth decade. This has been attributed to age related changes in both retina and rostral part of the visual system. (8) Migraine patients selected were in the interictal period, at least 72 hours after the last attack,(2) and had not received prophylactic antimigraine therapy or other drugs liable to affect the excitability of the central nervous system. All patients had normal or corrected visual acuity and had no other visual disorders. History regarding migraine including duration and frequency was computed using a proforma. Visual evoked potentials were measured in all subjects and controls in the Department of Neurology, Govt. Medical College, Thiruvananthapuram after clinical neurological examination including fundoscopy and external ocular movements. All subjects gave their informed consent and objectives of the test were explained prior to the session.

The study was approved by the Research Committee and Human Ethical Committee, Govt. Medical College, Thiruvananthapuram.

\section{Techniques}

Recording of VEP was done with Neuropack- $\Sigma$ Evoked potential measuring system (MEB-5500 series). Pattern Reversal-VEP recording was performed using a black and white checker board pattern displayed on a television monitor with pattern element size $14 \times 16 \mathrm{~min}$ and stimulus field size $>8$ deg. at a viewing distance of $100 \mathrm{~cm}$. Pattern reversal rate was 2 per second.

Subjects were encouraged to maintain attention and fixation throughout the procedure. Standard silver-silver chloride disc scalp electrodes were placed according to the International $10 / 20$ system. ${ }^{(9)}$
The active electrode was placed on the scalp along the midline at $\mathrm{OZ}$ position. ${ }^{\left({ }^{8}\right)}$ Reference electrode was placed at FZ and ground electrode on the forehead. Electrode impedance was kept below $5 \mathrm{kOhms}$. VEP responses were recorded by monocular stimulation and 500 responses averaged. A repeat trial was performed to verify reproducibility of the results.

Latency and amplitude of P100, the positive midoccipital peak that occurs at a mean latency of 100 milliseconds were analysed. Latency was measured in milliseconds from the onset of stimulus to the maximum positive deflection. P100 amplitude was measured in microvolts from the prestimulus baseline.

\section{Statistical Analysis}

Statistical analysis was performed using software (SPSS version 10). Analysis of variance was performed as a parametric test to compare different variables between three groups. Linear regression analysis was employed to express the relationship of various parameters with mean latency and amplitude of P100. For all statistical evaluations probability of value, $<0.05$ was considered significant. Chi square analysis, Student's t-test, One Way ANOVA with Duncan's Multiple Range Test, Correlation and Regression analyses were performed to elucidate the results of the study.

\section{RESULTS}

\begin{tabular}{|c|c|c|c|c|c|}
\hline Parameters & Category & Mean & \pm SD & \begin{tabular}{|c|}
$F$ \\
value
\end{tabular} & $\begin{array}{c}\mathbf{p} \\
\text { value }\end{array}$ \\
\hline \multirow{3}{*}{$\begin{array}{l}\text { VEP P100 } \\
\text { Latency RE }\end{array}$} & Without Aura & $101.74^{a}$ & 3.92 & \multirow{3}{*}{6.453} & \multirow{3}{*}{$<0.01$} \\
\hline & With Aura & $106.42^{b}$ & 6.99 & & \\
\hline & Control & \begin{tabular}{|l|}
$101.47^{a}$ \\
\end{tabular} & 3.35 & & \\
\hline \multirow{3}{*}{$\begin{array}{l}\text { VEP P100 } \\
\text { Latency LE }\end{array}$} & Without Aura & $101.73^{a}$ & 4.33 & \multirow{3}{*}{7.003} & \multirow{3}{*}{$<0.01$} \\
\hline & With Aura & $106.53^{b}$ & 6.83 & & \\
\hline & Control & $101.44^{\mathrm{a}}$ & 3.01 & & \\
\hline & Compari & 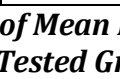 & 100 & en & \\
\hline
\end{tabular}

(One way ANOVA comparing different groups) *a, b - mean values with same superscript in each row do not differ each other (Duncan's Multiple Range Test)

The aura group of migraine displayed significant prolongation of VEP latency in the right and left eyes compared to both the without aura group and control groups $(\mathrm{p}<0.01)$. No significant difference in P100 latency was recorded between cases without aura and controls.

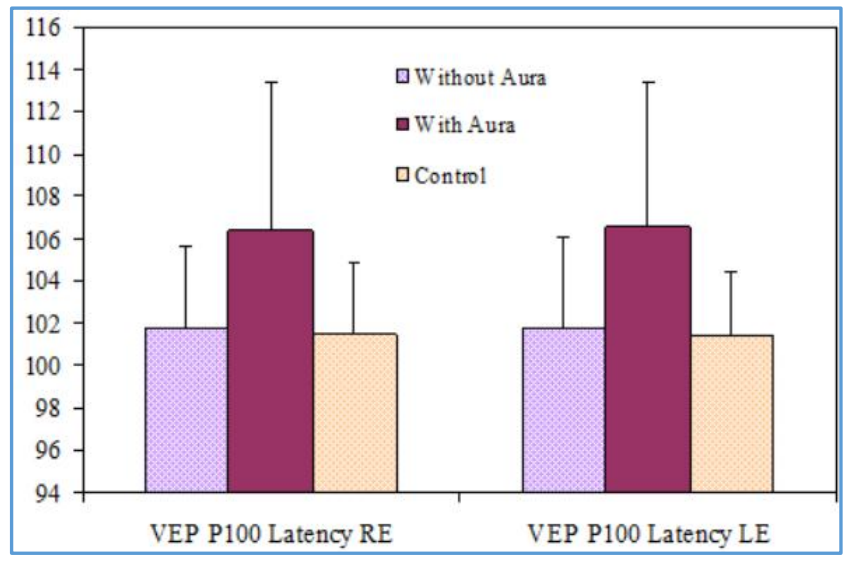

Figure 1. Mean VEP P100 Latency in the Three Tested Groups 


\begin{tabular}{|c|c|c|c|c|c|}
\hline Parameters & Category & Mean & \pm SD & $\begin{array}{c}F \\
\text { value }\end{array}$ & $\begin{array}{c}p \\
\text { value }\end{array}$ \\
\hline \multirow{3}{*}{$\begin{array}{c}\text { VEP P100 } \\
\text { Amplitude RE }\end{array}$} & Without Aura & $8.92^{\mathrm{a}}$ & 2.01 & \multirow{3}{*}{0.679} & \multirow{3}{*}{$>0.05$} \\
\hline & With Aura & $9.98^{a}$ & 3.00 & & \\
\hline & Control & $9.38^{a}$ & 2.76 & & \\
\hline \multirow{3}{*}{$\begin{array}{c}\text { VEP P100 } \\
\text { Amplitude LE }\end{array}$} & Without Aura & $9.02^{\mathrm{a}}$ & 1.87 & \multirow{3}{*}{0.270} & \multirow{3}{*}{$>0.05$} \\
\hline & With Aura & $9.45^{\mathrm{a}}$ & 2.70 & & \\
\hline & Control & $9.48^{a}$ & 2.54 & & \\
\hline
\end{tabular}

*a - mean values with same superscript in each row do not differ each other (Duncan's Multiple Range Test).

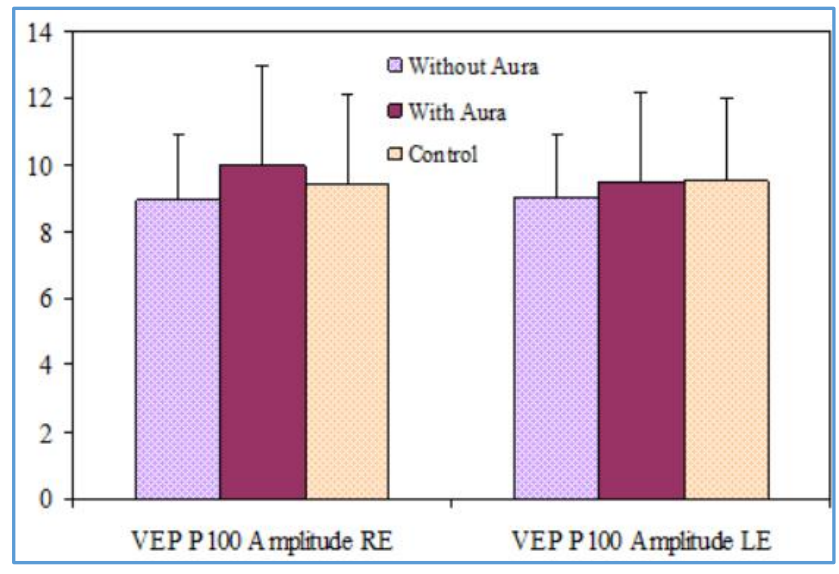

Figure 2. Mean VEP 100 Amplitude in the Three Tested Groups

VEP P100 amplitude showed no significant difference $(p>0.05)$ in mean value between case and control groups for right or left eyes.

No difference in P100 amplitude or latency was noted between males and females upon analysis. Mean latencies of VEP P 100 wave of right and left eyes showed no significant difference ( $p>0.05)$, when analysed among cases.

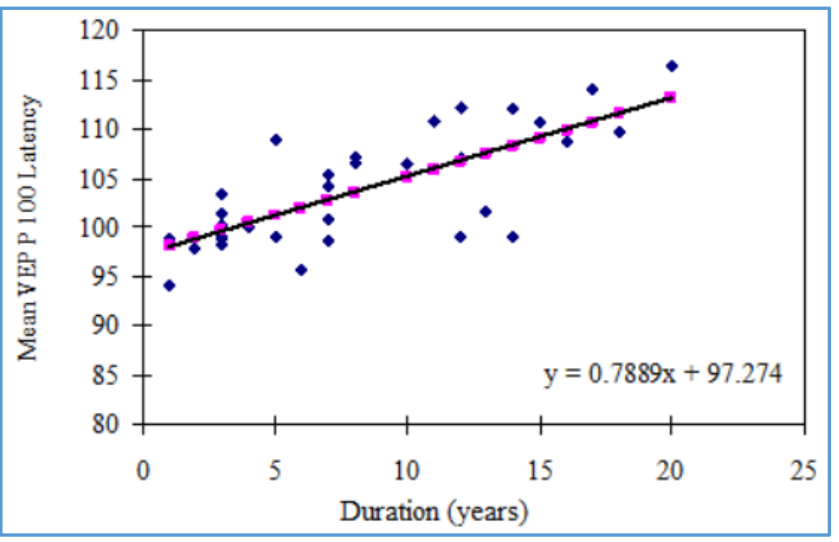

\section{Figure 3. Relationship between mean VEP P100} Latency and Disease Duration of Migraine

Disease duration of migraine showed a significant positive linear relationship with mean value of VEP P100 latency.

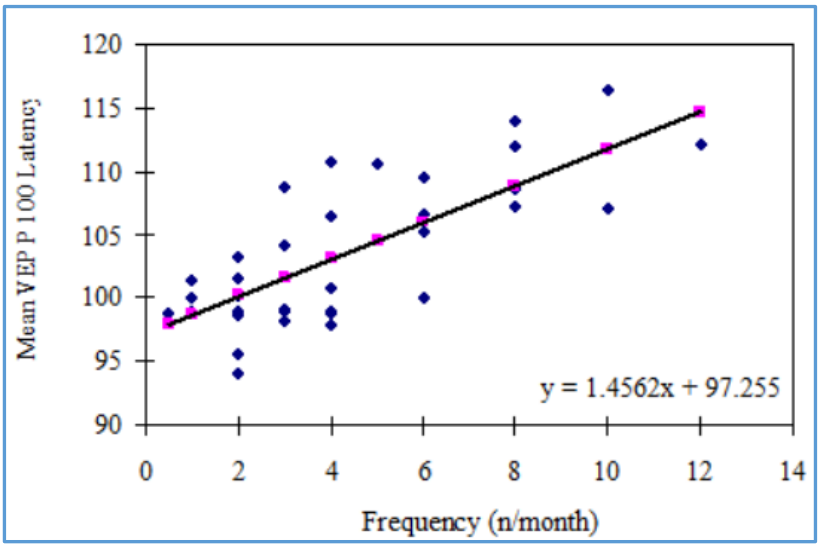

Figure 4. Relationship between mean VEP P100 Latency and Frequency of Migraine among Cases

Frequency of migraine showed a significant positive linear relationship with mean P 100 latency.

Even though mean P100 amplitude and disease duration showed a positive relationship, which was linear, the degree of relation was not significant. P 100 amplitude and frequency of migraine showed a negative relationship, which was linear, but the degree of relation was not significant.

\section{DISCUSSION}

Results of the study point to an association between VEP latency and migraine with aura. Mean latency of P100 was found to be significantly prolonged in migraine cases with aura compared to both the without aura group and controls. Visual aura suggests specific involvement of the visual system in migraine, and is viewed to be caused by regional neuronal depolarisation and the accompanying regional oligaemia observed with cortical spreading depression.(10) Kennard et al(5) who confirmed prolonged P100 latency in migraine patients suggested that the prolongation may have a structural basis, due to ischaemic damage during repeated attacks. Legg and Khalil also found that repeated migraine auras caused damage to the visual system, most likely at the cortical level. Khalil et al in their study found that subjects with migraine have constitutionally prolonged VEP latencies and increased P100 amplitude in migraine without aura regardless of duration of migraine, but amplitude declined to below normal in cases with a long history of migraine with aura. NMDA (N-methyl-D-aspartate) associated neurotoxicity, repeated transient hypoxia or even ischaemia were suggested as possible causes for injury to cortical neurons.(11) Although amplitude changes in VEP of migraine patients compared to controls have been reported in previous studies, the current study failed to replicate this finding, as did some other studies. $(2,12)$ Increased P100 amplitude in migraine patients has been hypothesised to be related to cortical spreading depression and hyperexcitability in the visual pathway by many researchers. $(13,14)$

The findings that migraine patients with aura showed significant delay in P100 latency, with no significant difference in P100 amplitude between patients and controls are similar to those by El Shater et al. No significant difference was observed between the right and the left eye in each group, which replicates the findings of the present study. The results were indicative of subtle neuronal damage to the visual system of migraine patients, particularly those 
with aura, which was attributed to recurrent cerebral hypoperfusion.(2)

In this study, duration of disease in years was found to be significantly high in the aura group with a mean value of 9.60 years compared to 5.68 years in without aura group. Highly significant $(p<0.001)$ difference was also revealed in frequency of attacks in the aura group (mean frequency $5.45 /$ month) compared to the group without aura, which has a mean frequency of $2.95 /$ month. These results reflect the fact that chances for escalation to a chronic course as well as the associated risk for a higher frequency of attacks was significantly more for the aura group of migraineurs. It has been reported that Pattern VEP, particularly the P100 latency are altered significantly in patients with numerous attacks and longer duration of migraine.(2) Sand and colleagues(15) found that P100 latency correlated positively with headache history duration. Repetitive Cortical Spreading Depression is proposed as one of the mechanisms responsible for brain tissue changes in migraine, which may also play a role for the anatomical correlates of disease duration and severity.(16)

Bockowski et al who found longer P100 latencies and higher P100 amplitude interictally in migraine with aura, reported that the most important factor seems to be the duration of migraine. The visual dysfunction implicated by the changes in VEP was hypothesised to be due to repeated parenchymal insults during the aura.(17) Polisch et al concluded that the alteration of P100 latency in migraine patients correlated significantly with the prolonged aura.(18) Lahat et al determined VEP abnormalities in migraine patients under five years of age, and proposed that VEP latencies be used in the differential diagnosis of migraine.(19)

Discrepancies between the results of various studies are probably caused by factors like differences in selection of studied subgroups and differences in selection of controls. Another reason might be differences in parameters of stimulation, such as check size of pattern stimulus, stimulus intensity and frequency and positioning of electrodes. Most results; however, indicate a different responsiveness of the visual system in migraine patients.

In this study, the variations in interictal P100 latency with significant correlation to the attack frequency and disease duration reflect dysfunction of neuronal excitability and point to possible neuronal damage in migraine consequent to repeated abnormal cortical neuroelectric phenomena like cortical spreading depression and neurotransmitter dysfunction. VEP is thus a useful tool in migraine, which provides insight into the neurogenic mechanisms underlying migraine, along with their subtle neurological sequelae.

\section{CONCLUSION}

VEP could be regarded as a useful and reliable technique for assessment of the visual dysfunction in migraine. There is involvement of the visual pathway and more subtle neurological abnormalities in migraine with aura rather than migraine without aura and these subtypes of migraine may be differentiated on the basis of VEP. This non-invasive technique may also supplement the clinical workup of the migraine patient, serving as a possible indicator of the adequacy of treatment or need for prophylactic strategies. In this regard, VEP might be considered superior to several other techniques, being safe and simple.

\section{Acknowledgement}

Most indebted to Dr. S. R. Chandra, Former Professor and Head, Dept. of Neurology, Govt. Medical College, Thiruvananthapuram for her valuable lessons and encouragement during the conception of this study.

\section{REFERENCES}

[1] Sadock BJ, Sadock VA. Kaplan and Sadock's comprehensive textbook of Psychiatry. $8^{\text {th }}$ edn. Vol 1. Lippincott: Williams and Wilkins 2005.

[2] El-Shater MF, El-Naga A, Gaber A, et al. Migraine with and without aura: clinical and electrophysiological changes. Egypt J Neurol Psychiat Neurosurg 2006;43(1):575-81.

[3] Bramanti B, Grungo R, Vitetta A, et al. Migraine with and without aura: electrophysiological and functional neuroimaging evidence. Functional Neurology 2005;20(1):29-32.

[4] Walsh P, Kane N, Butler S. The clinical role of evoked potentials. J Neorol Neurosurg Psychiatry 2005;76(Suppl 2):1116-22.

[5] Kennard C, Gawel M, Rudolph Nde M, et al. Visual evoked potentials in migraine subjects. Res Clin Stud Headache 1987;6:73-80.

[6] Ashjazadeh N, Varavipour B. Abnormalities of visual evoked potentials in migraine patients. IJMS 2003;28(2):65-8.

[7] Headache Classification Subcommittee of the International Headache Society. The international classification of headache disorders: 2nd edn. Cephalalgia 2004;24(Suppl 1):9-160.

[8] Misra UK, Kalita J. Clinical neurophysiology. 2nd edn. Elsevier 2006:470.

[9] Odom V, Bach M, Barber C, et al. Visual evoked potentials standard (2004). Doc Ophthalmol 2004;108(2):115-23.

[10] Swaiman KF, Ashwal S, Ferriero DM. Paediatric neurology, principles and practice. $4^{\text {th }}$ edn. Vol 2. Mosby, Elsevier 2006.

[11] Khalil NM, Legg NJ, Anderson DJ. Long term decline of P100 amplitude in migraine with aura. J Neurol Neurosurg Psychiatry 2000;69(4):507-11.

[12] Raudino F. Visual evoked potential in patients with migraine. Headache: The Journal of Head and Face Pain 1988;28(8):531-3.

[13] Coppola G, Pierelli F, Schoenen J. Is the cerebral cortex hyperexcitable or hyperresponsive in migraine? Cephalalgia 2007;27(12):1427-39.

[14] Shibata K, Osawa M, Iwata M. Simultaneous recording of pattern reversal retinograms and visual evoked potentials in migraine. Cephalgia 1997;17(7):742-7.

[15] Sand T, Zhitniy N, White LR, et al. Visual evoked potential latency, amplitude and habituation in migraine: a longitudinal study. Clinical Neurophysiol 2008;119(5):1020-7. 
[16] Schmitz N, Admiraal-Behloul F, Arkink EB, et al. Attack frequency and disease duration as indicators for brain damage in migraine. Headache 2008;48(7):1044-55.

[17] Bockowski L, Sobaneic W, Smigielska-Kuzia J, et al. The pattern-reversal visual evoked potentials in children with migraine with aura and without aura. Rocz Akad Med Bialymst 2003;48:154-7.
[18] Polich J, Ehlers CL, Dalassio DJ. Pattern-shift visual evoked responses and EEG in migraine. Headache 1986;26(9):451-6.

[19] Lahat E, Barr J, Barzilai A, et al. Visual evoked potentials in the diagnosis of headache, before 5 years of age. Eur J Pediatr 1999;158(11):892-5. 